\title{
Environmental Correlates of Residential Satisfaction: An Exploration of Mismatched Neighborhood Characteristics in the Twin Cities
}

\author{
Xinyu (Jason) Cao \\ Northwest Land and Resources Research Center, Institute of Transport Geography and \\ Spatial Planning, Shaanxi Normal University, China \\ Humphrey School of Public Affairs, University of Minnesota, Twin Cities \\ $30119^{\text {th }}$ Ave. S, Minneapolis, MN, 55125, USA \\ cao@umn.edu \\ Donggen Wang \\ Department of Geography, Hong Kong Baptist University, Kowloon Tong, Kowloon, \\ Hong Kong. Email: dgwang@ hkbu.edu.hk
}

\begin{abstract}
:
Previous studies have overwhelmingly focused on the effects of objective and/or perceived neighborhood characteristics on residential satisfaction. Little attention has been paid to residential preferences and their realization. This study hypothesizes that residential satisfaction is different for individuals whose residence is located in a neighborhood with characteristics that match their preferences and those whose residence is located in a neighborhood with characteristics that do not match their preferences. Therefore, residential satisfaction depends upon whether perceived neighborhood characteristics match the resident's preferences for the characteristics. Using data from the Twin Cities, this study explores two related issues: the impact of mismatched neighborhood characteristics on residential satisfaction and the impact of perceived neighborhood characteristics on residential satisfaction. We find that using mismatched neighborhood characteristics or perceived neighborhood characteristics as explanatory variables produces somewhat different environmental correlates of residential satisfaction. Findings from this study suggest that improving parks and open space, neighborhood safety, and neighborhood appearance is important to enhance residential satisfaction of existing residents.
\end{abstract}

Key words: Campbell's model, subjective well-being; residential sorting; mismatch; built environment; land use

\section{Acknowledgements}

Data collection was supported by the Transitway Impact Research Program in the Twin Cities. Jessica Schoner helped with survey administration and ArcGIS application. The support of National Science Foundation of USA (\#1243535) and Faculty Research Grant of Hong Kong Baptist University (FRG2/14-15/011) are also acknowledged. The constructive comments from three anonymous reviewers and Editor Nassauer have greatly improved the paper. Thank Dr. Ryan Allen for his comments on the paper. 


\section{Introduction}

Residential satisfaction (including housing satisfaction and neighborhood satisfaction) has emerged periodically as a hot research topic in urban studies and geography (Galster, 1987; Heaton et al., 1979; Hur and Morrow-Jones, 2008; Lansing and Marans, 1969; Lu, 1999; Wang and Wang, 2015). An immense literature on residential satisfaction has been established over the past several decades. The mainstream literature suggests that in addition to socioeconomic characteristics, housing and neighborhood attributes are important correlates of residential satisfaction (Dekker et al., 2011; Parkes et al., 2002).

Some studies find that residential satisfaction has small variations among residents living in different neighborhoods (McCrea et al., 2014; McCrea et al., 2005) and that residents are satisfied even when they live in poor conditions (Amérigo and Aragonés, 1990; Amos et al., 1982; Jansen, 2013). They argue that residents choose residential places that meet their needs (or preferences) the best and hence are satisfied (Amérigo and Aragonés, 1997; McCrea et al., 2014). Therefore, residential preferences seem to play a role in affecting residential satisfaction because residents tend to self-select into neighborhoods that match their residential preferences.

Many previous studies have examined the influences of objectively measured or perceived neighborhood characteristics on residential satisfaction, but few have investigated the effect of residential preferences. Residential choice consists of a tradeoff among neighborhood characteristics because of financial constraints and limited housing options; therefore, many residents are not able to choose the housing and neighborhoods they prefer (Cho and Rodriguez, 2014; Schwanen and Mokhtarian, 2004). People with realized residential preferences may be more satisfied than those with unrealized preferences. Thus, a few questions emerge: How are residential preferences related to residential satisfaction? Are there significant differences in the satisfaction between people whose residences match their preferences and those whose residences are incongruent with their preferences?

To address these questions, this study employs the conceptual model developed by Campbell et al. (1976) that emphasizes the impacts of evaluated neighborhood characteristics on residential satisfaction. According to Campbell et al. (1976), evaluated neighborhood characteristics are the assessments of perceived neighborhood characteristics against a resident's internal standards. Using 2011 data from the Minneapolis and St. Paul metropolitan area (Twin Cities), this study constructs mismatched neighborhood characteristics (a binary measure for each of the neighborhood characteristics to indicate that a resident' preference for the neighborhood characteristic exceeds her perception of the neighborhood characteristic) to represent evaluated neighborhood characteristics. It first explores environmental correlates of residential satisfaction. we also compare the influences of neighborhood characteristics on the satisfaction of residents who stayed in the neighborhoods for different time periods, to capture the possible effects of residential experience on residential satisfaction (Jansen, 2013). 


\section{Literature Review and Conceptual Framework}

Residential satisfaction is an important component of life satisfaction. It reflects individuals' satisfied or dissatisfied responses to the residential environment that is comprised of housing and the neighborhood (Campbell et al., 1976). Understanding the determinants of residential satisfaction has important implications for planners to identify the policies and neighborhood design that can improve residents' quality of life. As such, it is not surprising that many studies have attempted to explain why people are satisfied or dissatisfied with their residential environment (for comprehensive reviews of relevant studies, see: (Dekker et al., 2011; Lu, 1999; Parkes et al., 2002; Wang and Wang, 2015)).

Previous studies have concluded that housing and neighborhood characteristics are important correlates of residential satisfaction. The size and quality of one's dwelling are positive contributors to housing satisfaction (Dekker et al., 2011; Li and Song, 2009), and housing age is negatively associated with housing satisfaction (Campbell et al., 1976; Lu, 1999). Social characteristics (e.g., social attachment and social contact with neighbors) and physical characteristics (e.g., the presence, location, and accessibility of shops and schools) of neighborhoods also affect residential satisfaction (Basolo and Strong, 2002; Dekker et al., 2011; Parkes et al., 2002).

Perceived neighborhood characteristics are associated with neighborhood satisfaction (e.g., attractive appearance and safety in Lovejoy et al. (2010)). Perceived neighborhood characteristics are individuals' cognitive understandings of objective neighborhood characteristics. Because perception is a mediating variable between objective neighborhood characteristics and neighborhood satisfaction (Campbell et al., 1976), it is not surprising that neighborhood perceptions are more important in explaining the variation in residential satisfaction than objectively-measured characteristics (Amérigo and Aragonés, 1997; Kahana et al., 2003; Lu, 1999). Cao (2015) applies a structural equations modeling approach to illustrate the mechanism under which objective neighborhood characteristics affect satisfaction with life. He concludes that objective neighborhood characteristics, including density, land use diversity, design, and amenities, affect perceived neighborhood characteristics, which in turn influence residential satisfaction and life satisfaction.

Activities and time use in the residential environment contribute to residential satisfaction. Spending more time in the neighborhood may increase residential satisfaction through enhancing social networks and building social contacts (e.g., Dekker et al., 2011). Kahana et al. (2003) argue that participating in neighborhood activities are positively associated with residential satisfaction. Hur and Morrow-Jones (2008) find that participation in organized neighborhood activities positively contributes to residential satisfaction. Jansen (2013) examines the effect of residential experience on satisfaction and finds that residents appreciate the housing situation in 
which they actually live more than one in which they do not have living experience. Wang and Wang (2015) analyze the contribution of the use and affective experience of the residential environment on residential satisfaction. They conclude that higher levels of valence and activation of activities conducted at home and in the neighborhood lead to more residential satisfaction. Because residential environments affect participation in activities within residential neighborhoods (Foster et al., 2014; Wang and Lin, 2013), residential environments affect residential satisfaction through their influence on activities and time use within residential neighborhoods.

Most previous studies implicitly assume that residents who are socioeconomically different and live in different types of houses and neighborhoods tend to have significantly different levels of residential satisfaction. However, residential satisfaction may not vary much between residents and places (McCrea et al., 2014; McCrea et al., 2005; Mitrany, 2005). For example, McCrea et al. (2005) state that most people in the Southeast Queensland region of Australia report being either "satisfied" or "very satisfied" with their housing and neighborhood and only a small percentage of residents are "dissatisfied"; a recent study in the same region demonstrates that overall satisfaction with urban living varies little between residents living in different types of urban environments (McCrea et al., 2014). It is evident that residents can be satisfied even when they live in poor housing conditions (Amérigo and Aragonés, 1990; Amos et al., 1982; Jansen, 2013) because they chose the neighborhoods "which satisfy them on attributes important to them" under certain constraints (McCrea et al., 2014, p.87). Therefore, residential preferences, which measure what people like (affection) or want (personal needs) from residential environments are relevant to residential satisfaction.

Few studies have considered the impacts of residential preferences on residential satisfaction. Kahana et al. (2003) argue that the congruence between personal preferences (or needs) and environmental attributes is an important determinant of the residential satisfaction of seniors living in different community settings. People may be dissatisfied if they do not get what they really want in their residential neighborhoods. They further contend that the congruence can be assessed along several salient physical and social dimensions including amenities, social interactions, safety, and so on. This argument is in line with Campbell's model (1976), a prevailing framework in the field of life satisfaction. As shown in the upper diagram of Figure 1, an individual experiences objective attributes (the stimuli) of a domain, perceives the stimuli through a cognitive process, assesses the attributes based on her perception and internal standards of comparison (including aspirations and expectations), and then decides whether she is satisfied with the domain. When people evaluate neighborhood characteristics, they often compare the characteristics they want to what they actually have (perceived neighborhood characteristics). Therefore, individuals' preferences or desires for neighborhood characteristics are one measure of the standards of comparison (see the lower diagram of Figure 1). If individuals' perceived neighborhood characteristics do not meet their preferences for the 
characteristics (i.e., the characteristics are mismatched), dissatisfaction begins to accumulate (Kahana et al., 2003). Therefore, residential match (or congruence), a joint outcome of residential preferences and perceived neighborhood characteristics, seems to have an effect on residential satisfaction.

\section{[Insert Figure 1 here]}

These assumptions are consistent with the importance-performance-analysis (IPA) approach in the literature on customer satisfaction (Matzler et al., 2003). To determine service improvement priority, service attributes can be classified based on the importance and performance of the attributes. Specifically, using a two-dimensional matrix where the $\mathrm{x}$-axis measures performance and the y-axis depicts importance, attributes can be grouped into four quadrants (Figure 2). Attributes with high importance and high performance are key drivers achieving satisfaction; those with high importance but low performance represent improvement priorities; those with low importance but high performance are possible overkill; and those with low importance and low performance represent tolerable disadvantages (Matzler et al., 2003). Accordingly, service improvement should focus on the attributes with high importance but low performance mismatched attributes. In the context of planning for residential satisfaction enhancement, limited resources should be directed towards mismatched neighborhood characteristics.

\section{[Insert Figure 2 here]}

To our knowledge, few studies have explicitly examined the empirical connections between the level of congruence between perceived and preferred neighborhood characteristics and residential satisfaction. Heaton et al. (1979) find residential preference realization (a proxy for residential match) has an effect on the intention to move (an implicit indicator of residential dissatisfaction). Jansen (2013) reports that residents living in a housing situation that is consistent with their preferences have higher appreciation scores (a proxy for residential satisfaction) for their dwelling than mismatched residents have.

Furthermore, residential preferences are dynamic over the length of stay in a neighborhood. Residents may adjust psychologically to become satisfied with where they live by, for example, lowering their aspirations (cognitive restructuring) or appreciating what they already have (Amérigo and Aragonés, 1997; Amos et al., 1982; Jansen, 2013; Priemus, 1986). That is, residents may adapt their preferences to their neighborhood characteristics and become congruent with them. Conversely, residents' preferences may change after staying in a neighborhood for a long time; for example, individuals' preferences for access to a playground may change after their child does not use it any more. This tends to increase residential incongruence. Residents typically relocate when the incongruence grows to a certain level. Therefore, long-term and short-term residents may have different environmental correlates of 
residential satisfaction. Accordingly, it is necessary to conduct in-depth analyses on residential match for different segments of residents so that we can broaden our understanding of the impacts of neighborhood characteristics on residential satisfaction.

Although it is important to integrate neighborhood perceptions and preferences, previous studies have often ignored the role of residential preferences in residential satisfaction and focus only on the impacts of perceived (and/or objective) neighborhood characteristics on residential satisfaction (e.g., Lovejoy et al., 2010). This study explores the effect of mismatched neighborhood characteristics on residential satisfaction and compares the results with the conventional approach of considering only perceived neighborhood characteristics.

\section{Methodology}

\subsection{Data and Variables}

In May 2011, we mailed a ten-page survey to randomly selected households in three urban corridors and two suburban corridors in the Twin Cities (Figure 3). Since this study uses the same data as Cao (2015), the data and variables are presented similarly. The urban corridors are within about a half-mile of Hiawatha Avenue, Nicollet Avenue, and Bloomington Avenue in South Minneapolis. The three urban corridors, mainly developed before World War II, are similar in terms of regional location (Figure 3), street patterns (Figure 4) and transit access, and demographics (Table 1). A light rail transit (LRT) line runs on Hiawatha Avenue while Nicollet and Bloomington corridors are served by express and local buses. The suburban corridors, Coon Rapids and Burnsville, have similar incomes and rates of home ownership as the urban corridors, but the former were mainly developed in the 1970s. Coon Rapids is about 14 miles away from downtown Minneapolis and Burnsville is 17 miles away. In these suburban corridors, curvilinear streets are prevalent (Figure 4) and transit services are limited. Cluster sampling was chosen because the survey was designed primarily to examine the relationships between Hiawatha LRT and travel behavior. Two urban corridors and two suburban corridors are the controls for the Hiawatha corridor.

\section{[Insert Figures 3 and 4 here]}

We obtained two databases of addresses from AccuData Integrated Marketing, a commercial data provider (http://www.accudata.com): "movers" and "nonmovers." The movers included all current residents who moved to the corridor after 2004 when the Hiawatha LRT commenced. From this database, we randomly drew about 1,000 residents from the Hiawatha corridor and about 500 residents from each of the Nicollet, Bloomington, Coon Rapids, and Burnsville corridors. We drew the same numbers of nonmovers from the corridors (the nonmovers are not included in the movers list). We oversampled the Hiawatha corridor because the primary purpose of the survey is to explore the influence of the Hiawatha LRT on travel behavior. 
The survey and two reminder postcards (1 and 2 weeks later) were posted in May 2011. As an incentive for completing the survey, ten $\$ 50$ gift cards were given to respondents randomly drawn from the sample. The original database consisted of 6,017 addresses, but only 5,884 were valid. We achieved a $22.2 \%$ response rate based on valid addresses only, which is within the range of response rates of a typical survey administered to the general population (10-40\%) (Sommer and Sommer, 1997). Table 1 illustrates the characteristics of the sample and the 2010 Census. The sample contains a higher proportion of homeowners than the Census, although the percentages of owners across different corridors are similar. This is not surprising because $54.5 \%$ of the sample includes nonmovers, and more than $90 \%$ of nonmovers own their houses whereas only $72 \%$ of movers are homeowners. Respondents tend to have fewer children and a smaller household size than the population.

\section{[Insert Table 1 here]}

The variables used in this study include five categories: residential satisfaction, perceived neighborhood characteristics, residential preferences, mismatched neighborhood characteristics, and demographic characteristics. For residential satisfaction, survey respondents were asked to indicate how well the characteristics of their neighborhood meet the current needs of their household on a seven-point scale ranging from "extremely poorly" (1) to "extremely well" (7). The question was adapted from Lovejoy et al. (2010). Table 2 illustrates the shares of different residential satisfaction scales for movers and nonmovers. Because $5 \%$ of respondents (including Scales 1, 2, and 3 in Table 2) are dissatisfied with their neighborhoods, they are combined into a single category for the sake of modeling.

\section{[Insert Table 2 here]}

Regarding perceived neighborhood characteristics (PNCs), respondents reported how true 27 characteristics are for their current neighborhoods on a four-point scale from "not at all true" (1) to "entirely true" (4). The 27 statements cover attributes associated with dwelling, land use and transportation systems, safety, and so on. They were adapted from Lovejoy et al. (2010). The PNCs reflect fundamental differences in neighborhood design perceived by the respondents. Also, we asked respondents to indicate the importance of these items when (for movers)/if (for nonmovers) they were looking for a new place to live, denoted as residential preferences (RPs). RPs were measured on a four-point scale from "not at all important" (1) to "extremely important" (4). The comparison of individuals' PNCs and RPs indicates how well their current neighborhoods meet their preferences. Specifically, a neighborhood characteristic is considered mismatched if its RP is scaled as a 3 or 4 , and the scale of its PNC is a 1 or 2; otherwise, a neighborhood characteristic is considered matched. Therefore, mismatched neighborhood characteristics (MNCs) are binary variables, with 1 indicating mismatched. 
The survey contains a list of demographic characteristics including gender, age, education, employment status, mobility constraints, income, household structure, and so on.

\subsection{Modeling approach}

Since residential satisfaction is measured on an ordinal scale, we employ ordered response models to explore environmental correlates of residential satisfaction. Instead of modeling residential satisfaction directly, ordered response models assume that there is an underlying latent continuous variable, $\mathrm{Y}^{*}$, representing an individual's propensity for choosing her level of satisfaction (Daykin and Moffatt, 2002). $\mathrm{Y}^{*}$ is expressed in the following form:

$$
Y^{*}=\beta X+e
$$

where $\mathrm{X}$ is a vector of explanatory variables, $\beta$ is a vector of parameters, and $\mathrm{e}$ is the unobserved error term. The relationship between the latent $\mathrm{Y}^{*}$ and the observed $\mathrm{Y}$ is:

$Y=j$ if $\mu_{j-1}<Y^{*} \leq \mu_{j}, \mathrm{j}=0,1,2, \ldots, \mathrm{J}$,

where the $\mu_{j} \mathrm{~s}$ are threshold parameters, defined as $\mu_{-1}=-\infty, \mu_{J}=+\infty$, and $\mu_{j-1}<\mu_{j}$ for all $\mathrm{j}$.

Then the maximum likelihood approach is employed to estimate the unknown parameters.

The Veall-Zimmermann $\mathrm{R}^{2}$ was chosen as a goodness-of-fit measure for the models because it is better than McFadden $\mathrm{R}^{2}$ when the number of ordinal categories exceeds three (Veall and Zimmermann, 1996). It is calculated as follows:

$\mathrm{R}_{\mathrm{vz}}^{2}=\frac{[L(\beta)-L(C) N E 2 L(C)}{-L I C) / \mathrm{N}+2 L I B)-2 L I C)}$

where LL(c) is the log-likelihood for the model where all coefficients but thresholds are restricted to zero (equivalent to a constant-only model); $\operatorname{LL}(\beta)$ is the log-likelihood at convergence (i.e., the final model); $\mathrm{N}$ is the number of observations in the model.

\section{Results}

\subsection{Comparing the effects of PNCs and MNCs}

Table 3 presents two ordered logit models for residential satisfaction. Since the sample was collected from five neighborhoods, we used four neighborhood dummy variables to control for the spatial dependency of the sample, since respondents in the same neighborhood may share common attributes. The MNC model follows the conceptual model in Figure 1 and uses neighborhood dummies, demographics, and MNCs as explanatory variables, whereas the PNC model adopts the conventional approach and uses neighborhood dummies, demographics, and PNCs as explanatory variables. In both models, neighborhood dummies were kept in the models even if they were not significant. Although we tested all of the demographic variables measured in the survey, we kept only those significant at the 0.10 level to obtain parsimonious models. As shown in Table 3, three demographic variables are significant in the models. For specific 
neighborhood characteristics, we kept those characteristics significant in either of the two models to facilitate cross-model comparison. The $\mathrm{R}^{2}$ of both models is at the magnitude of $0.3 \sim 0.4$, and the PNC model has a somewhat better fit than the MNC model.

[Insert Table 3 here]

Next, we explore the model with PNCs as explanatory variables, commonly seen in the literature (Lovejoy et al., 2010). After controlling for demographics and neighborhood dummy variables eight PNCs are significant at the 0.05 level and one PNC (pertinent to upkeep) is marginally significant. Variables including safe neighborhood for walking, low crime rate within the neighborhood, attractive appearance of the neighborhood, high level of upkeep in the neighborhood, and lots of interaction among neighbors are significantly associated with residential satisfaction. These findings are consistent with Lovejoy et al. (2010), in which they are observed characteristics of safety, attractiveness, and liveliness factors. Safety and neighborhood attractiveness are critical determinants of residential location choice (Bina et al., 2006; Cao, 2008), so it is not surprising that safety- and attractiveness-related characteristics are significant. High levels of interactions with neighbors reflect a sense of community, which is an important dimension of quality of life. There is a significant association between residential satisfaction and parks and open spaces nearby. This is reasonable because several studies have concluded that neighborhood open spaces contribute to residential satisfaction (Ambrey and Fleming, 2014; Sugiyama et al., 2009). Shopping areas within walking distance are associated with residential satisfaction, which is consistent with Hur and Morrow-Jones (2008). The model also shows that religious or civil buildings nearby and living on cul-de-sacs have associations with residential satisfaction.

In the MNC model, religious or civil buildings nearby and living on cul-de-sacs become statistically insignificant. However, four variables insignificant in the PNC model become significant. Consistent with Lovejoy et al. (2010), mismatched quiet neighborhood and economic level of neighbors similar to my level are negatively associated with residential satisfaction. In a study in Northern California, neighborhood quietness was an important factor for residential location choice, right after affordability and safety (Cao, 2008). Therefore, it is plausible that quietness contributes to residential satisfaction. The significance of the economic level variable is consistent with the theory of neighborhood segregation: residents sort themselves according to their willingness to pay (O'Sullivan, 2012). Proximity to the workplace contributes to residential satisfaction, consistent with Hur and Morrow-Jones (2008). Similar to Parkes et al. (2002), school quality is associated with residential satisfaction. Overall, the MNC model shows that safety, attractiveness, accessibility, school quality, and neighbor interactions should be improved to enhance the residential satisfaction of existing residents. 
Since we standardized neighborhood characteristics when estimating the model, we can compare the relative importance of the characteristics affecting residential satisfaction. Safe neighborhood for walking and attractive appearance of neighborhood have the largest standardized coefficients among the neighborhood characteristics in the MNC model (Table 3). Therefore, they are the most important neighborhood characteristics for residential satisfaction, which is consistent with Lovejoy et al. (2010).

\subsection{Comparing movers and nonmovers}

Because residential preferences may change over time, long-term and short-term residents (movers and nonmovers here) were separately examined to determine whether they have different environmental correlates of residential satisfaction. The second column block in Table 4 illustrates nonmovers' and movers' mean scores of the 27 PNCs. The differences in mean scores are roughly evenly distributed in terms of their sign: 12 are negative and 15 are positive. However, nonmovers tend to have significantly stronger preferences for 25 neighborhood characteristics than movers. For MNCs, 18 characteristics are significantly different between nonmovers and movers, and nonmovers tend to have larger shares of MNCs than movers. These findings are reasonable because nonmovers have lived in the neighborhoods longer than movers. Nonmovers' prior residential choice is a result of the needs they had when they were looking for a place to live more than seven years ago, and their needs at that time likely differ from their current ones. On the other hand, movers' RPs are more likely to reflect their current needs than nonmovers', and their current neighborhoods tend to meet their needs if they had been able to self-select their residential neighborhood. Overall, these findings imply that individuals' preferences for neighborhood characteristics change over time.

[Insert Table 4 here]

Given the differences, we assume that movers and nonmovers show different patterns on environmental correlates of residential satisfaction. We developed three MNC models for the whole sample, nonmovers, and movers, respectively. We kept MNCs significant (at the 0.10 level) in any of the three models to enable cross-model comparisons. Table 5 illustrates that upkeep, neighborhood quietness, and access to downtown are significant for movers, but insignificant for nonmovers. On the other hand, walking safety, neighbor interactions, similar economic levels, access to local shopping, off-street parking, the crime rate, and school quality are significant only in the nonmover model. Since MNCs are more prevalent for nonmovers than for movers, it is reasonable that the nonmover model contains more neighborhood characteristics than the mover model. As residential preferences change, more and more neighborhood characteristics become incongruent, which leads to residential dissatisfaction. Once dissatisfaction reaches a threshold, people start to relocate and reach a new equilibrium with different tradeoffs. These findings provide additional empirical evidence that residential experience matters to satisfaction (Jansen, 2013). 
[Insert Table 5 here]

Table 5 also shows that improvement priorities differ between nonmovers and movers. For nonmovers, the top three neighborhood characteristics are walking safety, crime rate, and school quality. However, none of them are significant in the mover model. For movers, the top three characteristics are parks and open spaces nearby, neighborhood appearance, and upkeep, which rank tenth, fourth, and eleventh, respectively, in the nonmover model.

\section{Conclusions}

Many previous studies have explored environmental correlates of residential satisfaction by including objectively-measured or perceived neighborhood characteristics. This study employs Campbell's model and explores the correlates using mismatched neighborhood characteristics. The Campbell model highlights the relevance of residential match and the importanceperformance analysis points to the key role of mismatched attributes (those with high importance but low performance) in service improvement priority. As far as we know, this is the first study that combines the Campbell model and IPA theory in the field. Using data from the Twin Cities, it compares MNC correlates and PNC correlates of residential satisfaction, and MNC correlates for two groups of residents.

Do MNC correlates of residential satisfaction differ from PNC correlates? Table 3 shows that seven neighborhood characteristics are significant in both PNC and MNC models, and the remaining six are significant only in one of the two models. Therefore, using PNC and MNC tends to yield different environmental correlates. Given the differences, which set of neighborhood characteristics should planners use to enhance residential satisfaction? According to the Campbell model and IPA theory, planners should concentrate on significant MNCs. These characteristics are important to residents' location choice but tend to show low performance. Prioritizing key MNCs can efficiently serve the unmet needs of existing residents. At the same time, both MNC and PNC models highlight the same top two characteristics (in terms of the relative weight of standardized coefficients). This implies that the two approaches may yield similar improvement priorities. However, repetitive studies in other regions are recommended to rule out the possibility of coincidence.

With a limited budget for residential satisfaction enhancement, this study points to prioritizing improvements in walking safety and neighborhood appearance. Complete Street programs can be adopted to enhance walking safety. Engineering solutions include paved sidewalks, marked crosswalks, crossing islands, and so on. Traffic calming and road diets can also help. Education (such as yard signs and pace car campaigns) and enforcement are also important to improve walking safety. Neighborhood residents can help improve walking safety through volunteer programs such as neighborhood speed watch and school crossing guards (Sandt et al., 2015). 
Overall, a package of multiple strategies is desirable to achieve the best outcome. Neighborhood appearance can be enhanced through landscaping, property repairs, and clean-up programs for streets, alleys, streams, parks, etc. Some programs can achieve both goals. For example, planting trees beautifies neighborhoods and provides a buffer between pedestrians and vehicular traffic.

A comparison of the models for movers and nonmovers indicates that different segments of residents have different environmental correlates of residential satisfaction. The models also suggest different neighborhood improvement priorities. Although the model for the whole sample highlights neighborhood appearance and walking safety, neighborhood beatification appears to be more critical for movers than for nonmovers, whereas walking safety enhancement will benefit nonmovers the most. Further, low crime and school quality are key neighborhood characteristics for nonmovers, and parks and open spaces and high upkeep are improvement priorities for movers. The different priorities seem to present a dilemma to planners to serve existing residents. We contend that the top unmet needs for both groups should be prioritized and based on the results of this study that means attention to safety, parks and open spaces, and neighborhood beatification. However, because of the scarce research on residential experience, we have a very limited understanding of the role that dynamic residential preferences play in residential satisfaction, and this question merits further investigation. 


\section{References}

Amérigo, M., Aragonés, J.I., 1990. Residential satisfaction in council housing. Journal of Environmental Psychology 10, 313-325.

Amérigo, M.a., Aragonés, J.I., 1997. A THEORETICAL AND METHODOLOGICAL APPROACH TO THE STUDY OF RESIDENTIAL SATISFACTION. Journal of Environmental Psychology 17, 47-57.

Ambrey, C., Fleming, C., 2014. Public Greenspace and Life Satisfaction in Urban Australia. Urban Studies 51, 1290-1321.

Amos, O., Jr., Hitt, M., Warner, L., 1982. Life satisfaction and regional development: A case study of Oklahoma. Social Indicators Research 11, 319-331.

Basolo, V., Strong, D., 2002. Understanding the neighborhood: From residents' perceptions and needs to action. Housing Policy Debate 13, 83-105.

Bina, M., Warburg, V., Kockelman, K., 2006. Location Choice vis-à-vis Transportation: Apartment Dwellers. Transportation Research Record: Journal of the Transportation Research Board 1977, 93-102.

Campbell, A., Converse, P., Rodgers, W., 1976. The Quality of American Life: Perceptions, Evaluations and Satisfactions. Russell Sage Foundation, New York.

Cao, X., 2008. Is Alternative Development Undersupplied? Examination of Residential Preferences and Choices of Northern California Movers. Transportation Research Record: Journal of the Transportation Research Board 2077, 97-105.

Cao, X., 2015. How does neighborhood design affect life satisfaction? Evidence from Twin Cities. Travel Behaviour and Society.

Cho, G.-H., Rodriguez, D.A., 2014. The influence of residential dissonance on physical activity and walking: evidence from the Montgomery County, MD, and Twin Cities, MN, areas. Journal of Transport Geography 41, 259-267.

Daykin, A.R., Moffatt, P.G., 2002. Analyzing ordered responses: A review of the ordered probit model. Understanding Statistics 1, 157-166.

Dekker, K., de Vos, S., Musterd, S., van Kempen, R., 2011. Residential Satisfaction in Housing Estates in European Cities: A Multi-level Research Approach. Housing Studies 26, 479-499.

Foster, S., Pereira, G., Christian, H., Knuiman, M., Bull, F., Giles-Corti, B., 2014. Neighborhood Correlates of Sitting Time for Australian Adults in New Suburbs: Results From Reside. Environment and Behavior.

Galster, G., 1987. Identifying the Correlates of Dwelling Satisfaction: An Empirical Critique. Environment and Behavior 19, 539-568.

Heaton, T., Fredrickson, C., Fuguitt, G., Zuiches, J., 1979. Residential preferences, community satisfaction, and the intention to move. Demography 16, 565-573.

Hur, M., Morrow-Jones, H., 2008. Factors That Influence Residents' Satisfaction With Neighborhoods. Environment and Behavior.

Jansen, S.T., 2013. Why is Housing Always Satisfactory? A Study into the Impact of Preference and Experience on Housing Appreciation. Social Indicators Research 113, 785-805.

Kahana, E., Lovegreen, L., Kahana, B., Kahana, M., 2003. Person, Environment, and PersonEnvironment Fit as Influences on Residential Satisfaction of Elders. Environment and Behavior $35,434-453$.

Lansing, J.B., Marans, R.W., 1969. Evaluation of Neighborhood Quality. Journal of the American Institute of Planners 35, 195-199. 
Li, S.-m., Song, Y.-1., 2009. Redevelopment, displacement, housing conditions, and residential satisfaction: a study of Shanghai. Environment and planning. A 41, 1090-1108.

Lovejoy, K., Handy, S., Mokhtarian, P., 2010. Neighborhood satisfaction in suburban versus traditional environments: An evaluation of contributing characteristics in eight California neighborhoods. Landscape and Urban Planning 97, 37-48.

Lu, M., 1999. Determinants of Residential Satisfaction: Ordered Logit vs. Regression Models. Growth and Change 30, 264-287.

Matzler, K., Sauerwein, E., Heischmidt, K., 2003. Importance-performance analysis revisited: the role of the factor structure of customer satisfaction. The Service Industries Journal 23, 112-129. McCrea, R., Shyy, T.-K., Stimson, R.J., 2014. Satisfied Residents in Different Types of Local Areas: Measuring What's Most Important. Social Indicators Research 118, 87-101.

McCrea, R., Stimson, R.J., Western, J., 2005. Testing a Moderated Model of Satisfaction with Urban Living using Data for Brisbane-South East Queensland, Australia. Social Indicators Research 72, 121-152.

Mitrany, M., 2005. High density neighborhoods: Who enjoys them? GeoJournal 64, 131-140.

O'Sullivan, A., 2012. Urban Economics, 8th ed. McGraw-Hill/Irwin, New York.

Parkes, A., Kearns, A., Atkinson, R., 2002. What Makes People Dissatisfied with their Neighbourhoods? Urban Studies 39, 2413-2438.

Priemus, H., 1986. Housing As a Social Adaptation Process: A Conceptual Scheme. Environment and Behavior 18, 31-52.

Sandt, L., Thomas, L., Langford, K., Nabors, D., 2015. A resident's Guide for Creating Safer Communities for Walking and Biking. Federal Highway Administration, Washington, DC.

Schwanen, T., Mokhtarian, P.L., 2004. The extent and determinants of dissonance between actual and preferred residential neighborhood type. Environment and Planning B-Planning \& Design 31, 759-784.

Sommer, B.B., Sommer, R., 1997. A practical guide to behavioral research: tools and techniques, 4th ed. Oxford University Press, New York.

Sugiyama, T., Thompson, C.W., Alves, S., 2009. Associations Between Neighborhood Open Space Attributes and Quality of Life for Older People in Britain. Environment and Behavior 41, 3-21.

Veall, M.R., Zimmermann, K.F., 1996. Pseudo-R2 Measures for Some Common Limited Dependent Variable Models. Sonderforschungsbereich 386.

Wang, D., Lin, T., 2013. Built environments, social environments, and activity-travel behavior: a case study of Hong Kong. Journal of Transport Geography 31, 286-295.

Wang, D., Wang, F., 2015. Contributions of the Usage and Affective Experience of the Residential Environment to Residential Satisfaction. Housing Studies. 
List of Tables

Table 1 Demographic Characteristics of Five Corridors, based on the Sample and the 2010

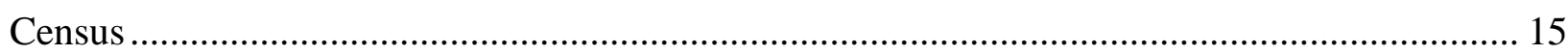

Table 2 Share of Residential Satisfaction in the Sample ....................................................... 16

Table 3 Models for Different Measures of Neighborhood Characteristics.............................. 17

Table 4 Neighborhood Characteristics of Nonmovers and Movers......................................... 18

Table 5 Models of Mismatched Neighborhood Characteristics for Movers and Nonmovers ...... 19 
Table 1 Demographic Characteristics of Five Corridors, based on the Sample and the 2010 Census

\begin{tabular}{lllllllllll}
\hline & \multicolumn{2}{l}{ Hiawatha } & Nicollet & \multicolumn{3}{c}{ Bloomington } & \multicolumn{2}{c}{ Coon Rapids } & \multicolumn{2}{c}{ Burnsville } \\
& Census & Sample & Census & Sample & Census & Sample & Census & Sample & Census & Sample \\
\hline Number of people & 24,166 & 508 & 36,808 & 197 & 27,055 & 241 & 24,866 & 175 & 27,975 & 182 \\
Percent of female & $50 \%$ & $52 \%$ & $49 \%$ & $49 \%$ & $50 \%$ & $51 \%$ & $51 \%$ & $49 \%$ & $52 \%$ & $49 \%$ \\
Mean household size & 2.27 & 2.15 & 2.50 & 2.21 & 2.65 & 2.26 & 2.53 & 2.42 & 2.31 & 2.24 \\
Percent with kids & $26 \%$ & $23 \%$ & $43 \%$ & $22 \%$ & $35 \%$ & $24 \%$ & $32 \%$ & $29 \%$ & $35 \%$ & $22 \%$ \\
Percent of owner & $68 \%$ & $83 \%$ & $49 \%$ & $82 \%$ & $62 \%$ & $84 \%$ & $77 \%$ & $86 \%$ & $58 \%$ & $84 \%$ \\
\hline
\end{tabular}


Table 2 Share of Residential Satisfaction in the Sample

\begin{tabular}{lll}
\hline Residential Satisfaction & Movers & Nonmovers \\
\hline 1: Extremely poorly & 0.3 & 0.9 \\
2 & 1 & 1.2 \\
3 & 3.7 & 3.1 \\
4: Neutral & 7.3 & 9.9 \\
5 & 25.4 & 19.5 \\
6 & 41.8 & 37.8 \\
7: Extremely well & 20.4 & 27.8 \\
\hline Total number of & & \\
observations & 574 & 688 \\
\hline
\end{tabular}

Note: Residential satisfaction indicates how well the characteristics of respondents' neighborhood meet the current needs of their household on a seven-point scale ranging from "extremely poorly" (1) to "extremely well" (7). 
Table 3 Models for Different Measures of Neighborhood Characteristics

\begin{tabular}{|c|c|c|c|c|}
\hline \multirow[t]{2}{*}{ Variables } & \multicolumn{2}{|c|}{$\begin{array}{c}\text { Mismatch } \\
\text { neighborhood } \\
\text { characteristics }\end{array}$} & \multicolumn{2}{|c|}{$\begin{array}{c}\text { Perceived } \\
\text { neighborhood } \\
\text { characteristics }\end{array}$} \\
\hline & Beta & P-value & Beta & P-value \\
\hline Threshold 1 & -2.132 & 0.000 & -2.439 & 0.000 \\
\hline Threshold 2 & -0.842 & 0.004 & -1.184 & 0.000 \\
\hline Threshold 3 & 0.880 & 0.002 & 0.524 & 0.071 \\
\hline Threshold 4 & 3.062 & 0.000 & 2.832 & 0.000 \\
\hline \multicolumn{5}{|l|}{ Fixed Effects } \\
\hline Bloomington & -0.031 & 0.855 & -0.032 & 0.851 \\
\hline Nicollet & 0.163 & 0.376 & 0.141 & 0.441 \\
\hline Coon Rapids & -0.890 & 0.000 & -0.584 & 0.004 \\
\hline Burnsville & -0.153 & 0.418 & 0.046 & 0.819 \\
\hline \multicolumn{5}{|l|}{ Demographics } \\
\hline Limitations on driving & -0.956 & 0.009 & -0.840 & 0.018 \\
\hline Age & 0.029 & 0.000 & 0.021 & 0.000 \\
\hline Household income & 0.049 & 0.077 & 0.054 & 0.049 \\
\hline \multicolumn{5}{|l|}{ Neighborhood Characteristics } \\
\hline Safe neighborhood for walking & -0.285 & 0.000 & 0.241 & 0.004 \\
\hline Attractive appearance of neighborhood & -0.275 & 0.000 & 0.391 & 0.000 \\
\hline Lots of interaction among neighbors & -0.195 & 0.002 & 0.182 & 0.009 \\
\hline Parks and open spaces nearby & -0.193 & 0.004 & 0.160 & 0.015 \\
\hline Close to where I work & -0.178 & 0.003 & -0.013 & 0.834 \\
\hline Low crime rate within neighborhood & -0.176 & 0.011 & 0.225 & 0.007 \\
\hline High level of upkeep in neighborhood & -0.171 & 0.011 & 0.154 & 0.058 \\
\hline Quiet neighborhood & -0.155 & 0.018 & 0.083 & 0.268 \\
\hline Economic level of neighborhoods similar to my level & -0.140 & 0.022 & 0.095 & 0.137 \\
\hline High quality k-12 schools & -0.133 & 0.029 & 0.093 & 0.174 \\
\hline Shopping areas within walking distance & -0.111 & 0.072 & 0.237 & 0.000 \\
\hline Religious or civic buildings (ex., library) nearby & -0.069 & 0.264 & 0.187 & 0.004 \\
\hline Living unit on cul-de-sac rather than through street & -0.001 & 0.988 & -0.180 & 0.006 \\
\hline Number of observations & 1010 & & 1055 & \\
\hline Veall-Zimmermann $\mathrm{R}^{2}$ & 0.333 & & 0.381 & \\
\hline
\end{tabular}


Table 4 Neighborhood Characteristics of Nonmovers and Movers

\begin{tabular}{|c|c|c|c|c|c|c|c|c|c|}
\hline \multirow[t]{2}{*}{ Neighborhood Characteristics } & \multicolumn{2}{|c|}{ Perceptions } & \multirow[b]{2}{*}{ Diff. } & \multicolumn{3}{|c|}{ Preferences } & \multicolumn{3}{|l|}{ Mismatch } \\
\hline & Nonmover & Mover & & Nonmover & Mover & Diff. & Nonmover & Mover & Diff. \\
\hline Living unit on cul-de-sac rather than through street & 1.49 & 1.37 & $0.12 *$ & 1.84 & 1.41 & $0.43 *$ & $18.2 \%$ & $6.9 \%$ & $11.3 \% *$ \\
\hline High quality k-12 schools & 2.69 & 2.53 & $0.16^{*}$ & 2.36 & 2.14 & $0.22 *$ & $15.5 \%$ & $13.8 \%$ & $1.7 \%$ \\
\hline Attractive appearance of neighborhood & 3.01 & 2.89 & $0.12 *$ & 3.52 & 3.26 & $0.26^{*}$ & $18.9 \%$ & $21.3 \%$ & $-2.4 \%$ \\
\hline Variety in housing styles & 2.94 & 2.87 & 0.07 & 2.92 & 2.47 & $0.45^{*}$ & $16.6 \%$ & $9.2 \%$ & $7.4 \% *$ \\
\hline High level of upkeep in neighborhood & 2.90 & 2.83 & 0.07 & 3.43 & 3.19 & $0.24 *$ & $25.8 \%$ & $22.0 \%$ & $3.9 \%$ \\
\hline Large back yards & 2.31 & 2.16 & $0.15^{*}$ & 2.65 & 2.29 & $0.36^{*}$ & $29.5 \%$ & $18.0 \%$ & $11.5 \% *$ \\
\hline Lots of off-street parking (garages or driveways) & 2.91 & 2.96 & -0.05 & 3.27 & 2.91 & $0.36^{*}$ & $23.4 \%$ & $14.7 \%$ & $8.7 \% *$ \\
\hline Sidewalks throughout the neighborhood & 3.24 & 3.48 & $-0.24 *$ & 3.26 & 3.09 & $0.17 *$ & $10.4 \%$ & $4.4 \%$ & $6.0 \% *$ \\
\hline Good bicycle routes beyond the neighborhood & 3.23 & 3.45 & $-0.22 *$ & 2.87 & 2.75 & 0.12 & $11.7 \%$ & $4.8 \%$ & $6.9 \% *$ \\
\hline Good public transit service (bus or rail) & 3.30 & 3.49 & $-0.19 *$ & 3.13 & 2.96 & $0.17 *$ & $10.5 \%$ & $3.4 \%$ & $7.1 \% *$ \\
\hline Easy access to transit stop/station & 3.29 & 3.49 & $-0.20 *$ & 3.05 & 2.89 & $0.16^{*}$ & $10.4 \%$ & $3.6 \%$ & $6.8 \% *$ \\
\hline Parks and open spaces nearby & 3.55 & 3.59 & -0.04 & 3.52 & 3.32 & $0.20 *$ & $6.4 \%$ & $3.6 \%$ & $2.9 \% *$ \\
\hline Shopping areas within walking distance & 2.61 & 2.71 & -0.10 & 2.86 & 2.64 & $0.22 *$ & $24.2 \%$ & $15.7 \%$ & $8.6 \% *$ \\
\hline Easy access to a regional shopping mall & 2.94 & 2.90 & 0.04 & 2.69 & 2.20 & $0.49 *$ & $12.1 \%$ & $4.9 \%$ & $7.1 \% *$ \\
\hline Easy access to downtown & 3.18 & 3.34 & $-0.16^{*}$ & 2.71 & 2.80 & -0.09 & $6.9 \%$ & $4.4 \%$ & $2.4 \%$ \\
\hline Religious or civic buildings (ex., library) nearby & 3.21 & 3.11 & $0.10^{*}$ & 2.91 & 2.40 & $0.51 *$ & $8.8 \%$ & $7.2 \%$ & $1.6 \%$ \\
\hline Close to where I work & 2.61 & 2.77 & $-0.16^{*}$ & 2.84 & 2.97 & $-0.13 *$ & $21.1 \%$ & $16.8 \%$ & $4.3 \%$ \\
\hline Low crime rate within neighborhood & 2.79 & 2.74 & 0.05 & 3.70 & 3.33 & $0.37 *$ & $33.4 \%$ & $28.3 \%$ & $5.2 \% *$ \\
\hline Low level of car traffic on neighborhood streets & 2.55 & 2.55 & 0.00 & 3.33 & 2.82 & $0.51 *$ & $38.3 \%$ & $24.9 \%$ & $13.4 \% *$ \\
\hline Quiet neighborhood & 2.91 & 2.86 & 0.05 & 3.50 & 3.03 & $0.47 *$ & $25.4 \%$ & $19.3 \%$ & $6.1 \% *$ \\
\hline Good street lighting & 3.04 & 2.98 & 0.06 & 3.40 & 2.90 & $0.50 *$ & $16.6 \%$ & $13.7 \%$ & $2.9 \%$ \\
\hline Safe neighborhood for walking & 3.10 & 3.18 & $-0.08 *$ & 3.75 & 3.48 & $0.27 *$ & $18.2 \%$ & $12.0 \%$ & $6.2 \% *$ \\
\hline Safe neighborhood for kids to play outdoors & 3.05 & 3.06 & -0.01 & 3.38 & 2.82 & $0.56^{*}$ & $15.1 \%$ & $10.3 \%$ & $4.7 \% *$ \\
\hline Lots of interaction among neighbors & 2.63 & 2.60 & 0.03 & 3.03 & 2.52 & $0.51 *$ & $27.3 \%$ & $18.1 \%$ & $9.2 \% *$ \\
\hline Lots of people out and about within the neighborhood & 2.82 & 3.00 & $-0.18 *$ & 2.99 & 2.67 & $0.32 *$ & $21.7 \%$ & $9.2 \%$ & $12.5 \% *$ \\
\hline Diverse neighbors in terms of ethnicity, race, and age & 2.92 & 3.03 & $-0.11 *$ & 2.64 & 2.47 & $0.17 *$ & $11.3 \%$ & $10.0 \%$ & $1.3 \%$ \\
\hline Economic level of neighborhoods similar to my level & 2.79 & 2.77 & 0.02 & 2.69 & 2.33 & $0.36^{*}$ & $14.9 \%$ & $11.5 \%$ & $3.4 \%$ \\
\hline
\end{tabular}

$* \mathrm{p}<0.05$. 
Table 5 Models of Mismatched Neighborhood Characteristics for Movers and Nonmovers

\begin{tabular}{|c|c|c|c|c|c|c|}
\hline & \multicolumn{2}{|c|}{ All Respondents } & \multicolumn{2}{|l|}{ Nonmovers } & \multicolumn{2}{|c|}{ Movers } \\
\hline & Beta & P-value & Beta & P-value & Beta & P-value \\
\hline Threshold 1 & -2.099 & 0.000 & -3.058 & 0.000 & -2.081 & 0.000 \\
\hline Threshold 2 & -0.770 & 0.000 & -1.447 & 0.000 & -0.985 & 0.000 \\
\hline Threshold 3 & 0.906 & 0.714 & 0.172 & 0.086 & 0.833 & 0.821 \\
\hline Threshold 4 & 3.091 & 0.000 & 2.341 & 0.028 & 3.124 & 0.000 \\
\hline \multicolumn{7}{|l|}{ Fixed Effects } \\
\hline Bloomington & -0.042 & 0.799 & -0.101 & 0.671 & -0.106 & 0.658 \\
\hline Nicollet & 0.239 & 0.189 & 0.330 & 0.192 & 0.040 & 0.882 \\
\hline Coon Rapids & -0.850 & 0.000 & -0.845 & 0.001 & -1.125 & 0.000 \\
\hline Burnsville & -0.183 & 0.333 & -0.251 & 0.335 & -0.220 & 0.437 \\
\hline \multicolumn{7}{|l|}{ Demographics } \\
\hline Limitations on driving & -1.133 & 0.002 & -1.382 & 0.002 & -0.514 & 0.453 \\
\hline Age & 0.029 & 0.000 & 0.020 & 0.006 & 0.028 & 0.000 \\
\hline Income & 0.048 & 0.078 & 0.028 & 0.473 & 0.045 & 0.258 \\
\hline \multicolumn{7}{|l|}{ Mismatched Neighborhood Characteristics } \\
\hline Safe neighborhood for walking & -0.256 & 0.000 & -0.290 & 0.002 & -0.173 & 0.100 \\
\hline Low crime rate within neighborhood & -0.191 & 0.006 & -0.265 & 0.008 & -0.073 & 0.451 \\
\hline High quality k-12 schools & -0.135 & 0.025 & -0.258 & 0.002 & 0.044 & 0.644 \\
\hline Attractive appearance of neighborhood & -0.267 & 0.000 & -0.250 & 0.012 & -0.305 & 0.001 \\
\hline Lots of off-street parking (garages or driveways) & -0.103 & 0.098 & -0.233 & 0.004 & 0.079 & 0.428 \\
\hline Close to where I work & -0.185 & 0.002 & -0.185 & 0.018 & -0.221 & 0.018 \\
\hline Economic level of neighborhoods similar to my level & -0.122 & 0.046 & -0.184 & 0.029 & -0.139 & 0.137 \\
\hline Lots of interaction among neighbors & -0.171 & 0.005 & -0.164 & 0.044 & -0.157 & 0.109 \\
\hline Shopping areas within walking distance & -0.129 & 0.035 & -0.162 & 0.044 & -0.132 & 0.175 \\
\hline Parks and open spaces nearby & -0.244 & 0.000 & -0.146 & 0.096 & -0.391 & 0.000 \\
\hline High level of upkeep in neighborhood & -0.181 & 0.006 & -0.136 & 0.143 & -0.247 & 0.014 \\
\hline Quiet neighborhood & -0.135 & 0.037 & -0.083 & 0.348 & -0.202 & 0.039 \\
\hline Easy access to downtown & -0.039 & 0.543 & 0.053 & 0.515 & -0.224 & 0.039 \\
\hline Number of observations & 1020 & & 539 & & 481 & \\
\hline Veall-Zimmermann $\mathrm{R}^{2}$ & 0.334 & & 0.390 & & 0.298 & \\
\hline
\end{tabular}

Bolded variables are significant in only one of the models for nonmovers and movers. 


\section{Figure 1 Theoretical Models}

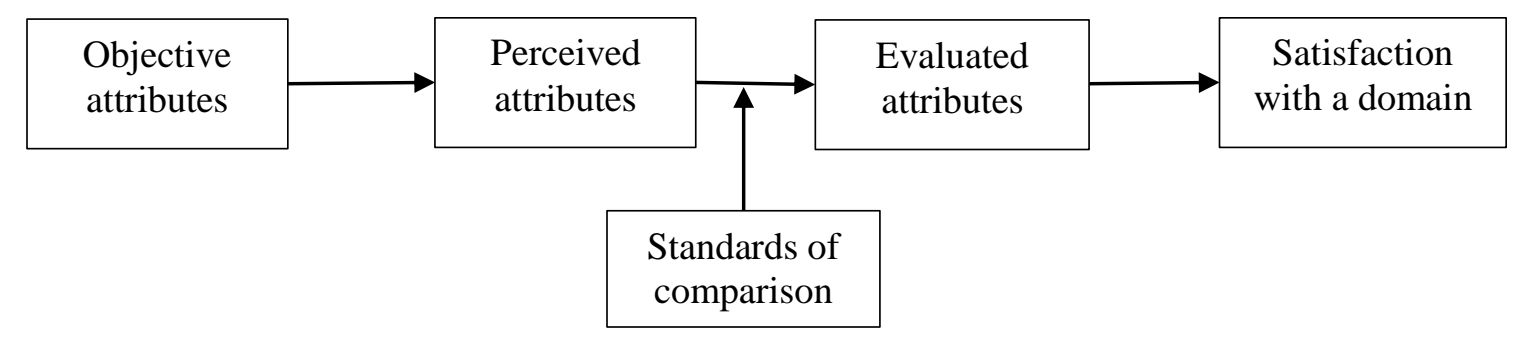

(a) Satisfaction with a domain

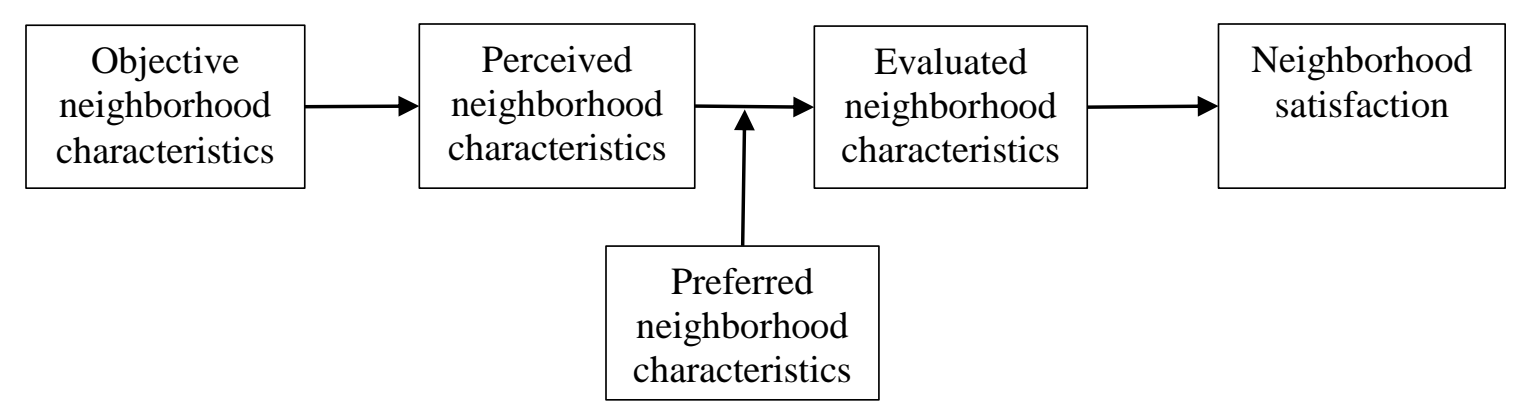

(b) Satisfaction with neighborhood

Based on Figure 1-1 in Campbell et al. (1976). Demographics are expected to affect all five dimensions and omitted from the conceptual models. 
Figure 2 Importance-Performance-Analysis

\begin{tabular}{|c|c|c|}
\hline \multirow{2}{*}{ High } & & \\
\hline & $\begin{array}{c}\text { Quadrant } 2 \\
\text { High Importance/Low Performance } \\
\text { High Priority }\end{array}$ & $\begin{array}{c}\text { Quadrant 1 } \\
\text { High Importance/High Performance } \\
\text { Key Drivers Achieving Satisfaction }\end{array}$ \\
\hline \multicolumn{3}{|l|}{ Importance } \\
\hline \multirow{3}{*}{ Low } & $\begin{array}{c}\text { Quadrant } 3 \\
\text { Low Importance/Low Performance } \\
\text { Tolerable Disadvantages }\end{array}$ & $\begin{array}{c}\text { Quadrant } 4 \\
\text { Low Importance/High Performance } \\
\text { Possible Overkill }\end{array}$ \\
\hline & & \\
\hline & Low & High \\
\hline
\end{tabular}


Figure 3 Hiawatha Corridor and Control Corridors

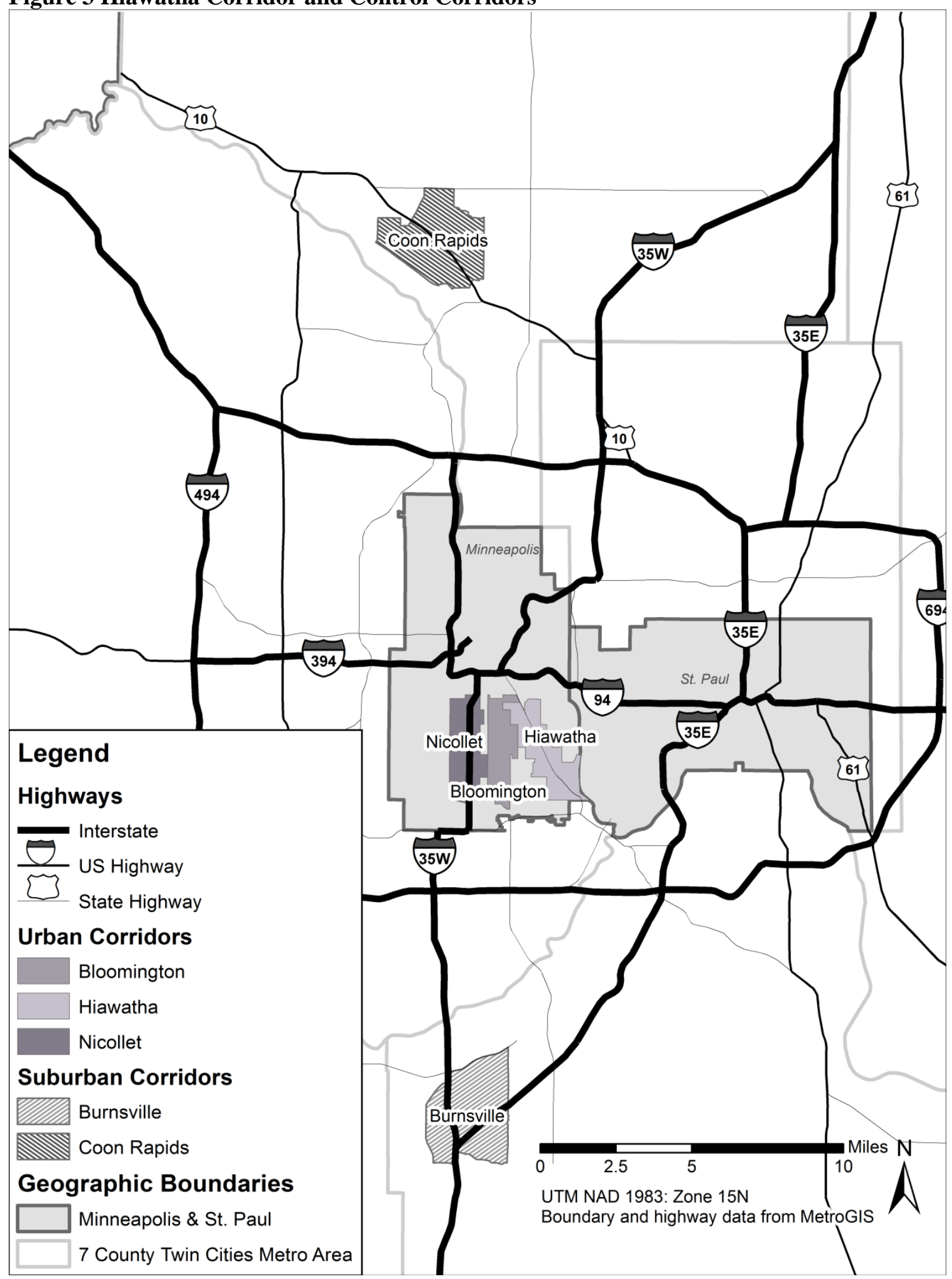


Figure 4 Map of Corridors

Hiawatha

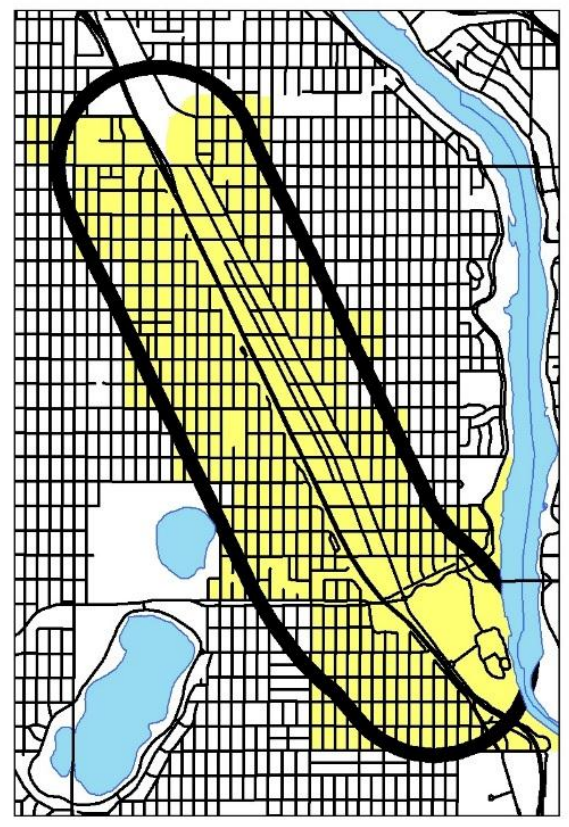

Bloomington

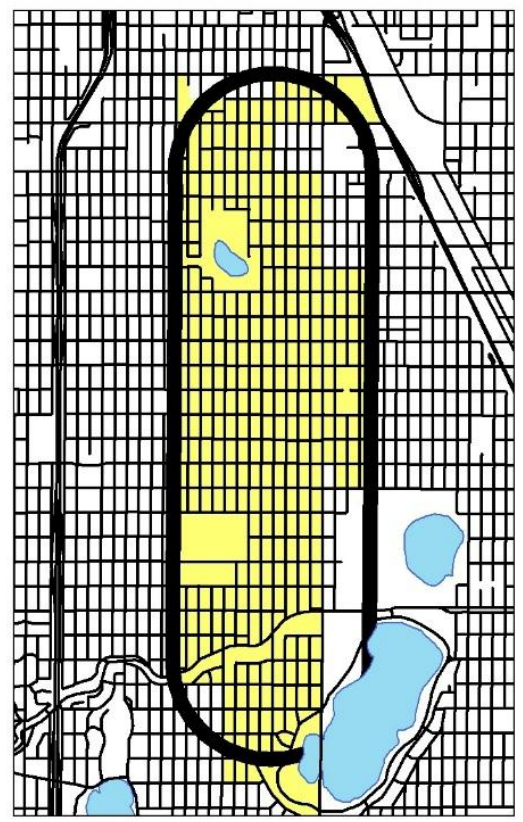

Nicollet

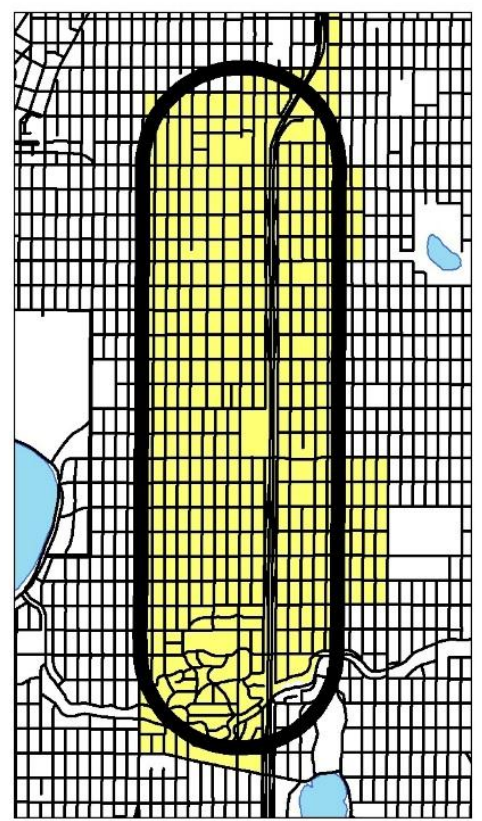

Coon Rapids

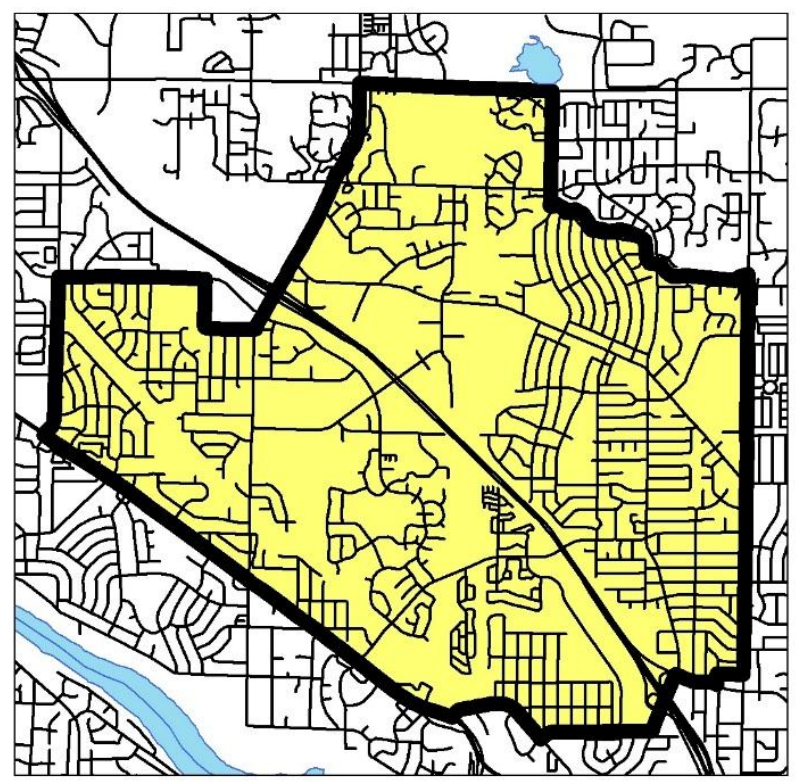

\section{Legend}

Study Corridor

Lakes \& Rivers

Street Network

\section{Burnsville}

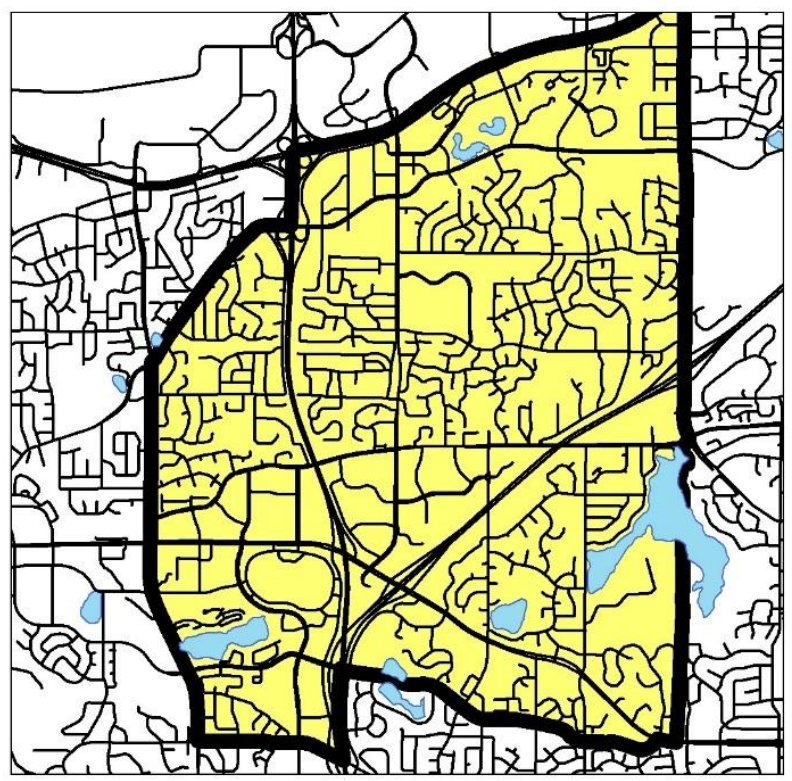

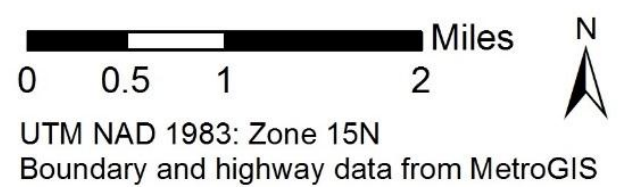

